\title{
Depositional model for mixed carbonate-clastic sediments in the Middle Cambrian Lower Zhangxia Formation, Xiaweidian, North China
}

\author{
Xingwen Zhang ${ }^{1,2}$, Xiongqi Pang ${ }^{1,2 \oplus *}$, Zhenkui Jin ${ }^{2}$, Tao $\mathrm{Hu}^{1,2}$, Abdulkareem Toyin ${ }^{2,3}$, Ke Wang ${ }^{4}$ \\ ${ }^{1}$ State Key Laboratory of Petroleum Resources and Prospecting, China University of Petroleum, Beijing 102249, P. R. China \\ ${ }^{2}$ College of Geosciences, China University of Petroleum, Beijing 102249, P. R. China \\ ${ }^{3}$ Department of Geology, Federal University Lokoja, Lokoja PMB 1154, Nigeria \\ ${ }^{4}$ School of Earth and Environmental Sciences, University of Manchester, Manchester M13 9PL, UK
}

Keywords:

Depositional model

mixed carbonate-clastic sediments

Middle Cambrian

the Lower Zhangxia Formation

Xiaweidian

North China

\section{Cited as:}

Zhang, X., Pang, X., Jin, Z., Hu, T.,

Toyin, A., Wang, K. Depositional model for mixed carbonate-clastic sediments in the Middle Cambrian Lower Zhangxia Formation, Xiaweidian, North China. Advances in Geo-Energy Research, 2019, 4(1): 29-42, doi:

10.26804/ager.2020.01.04.

\begin{abstract}
:
In order to make accurate decisions in interpreting depositional environments of sedimentary rocks, a multi-proxy approach is best employed. In the Middle Cambrian Lower Zhangxia Formation exposed at Xiaweidian in the Northern China, lack of this form of approach puts doubts on the various models (e.g., carbonate ramp and isolated platform) proposed by previous workers. In this study, we integrated field outcrop investigation with laboratory examinations of thin sections with light and electron microscopies to further understand sedimentary environments of the Lower Zhangxia Formation. Dominant rock types of this formation include oolitic limestone, muddy limestone, flat-pebble limestone and calcareous mudstone. Evidence from ooid features and lime-mud content of oolitic limestones suggests their deposition in an environment with intermittent high energy level. The muddy limestones were formed on a restricted platform with lower wave energy, which is supported by the existence of pyrites in a reducing environment and the input of terrestrial clays from neighboring clastic environments. The flat-pebble limestones were formed by storm reworking of early deposits on restricted platform below a fair-weather wave base, due to their composition and clast features. Mudstones with occurrences of terrestrial silts could be associated with clastic shallow marine adjacent to the restricted platform. A mixed carbonate-clastic depositional model is suggested for this formation and can be used as model for other researchers working in the North China.
\end{abstract}

\section{Introduction}

There are many factors needed to be considered in interpretation of depositional environment, so using a single approach instead of the multi-proxy approach could result into inappropriate interpretation. In a multi-proxy approach system, data of different forms are usually available and these will enhance the accuracy of interpretation. However, the lack of this approach applied in interpreting sedimentary environments of the Middle Cambrian Zhangxia Formation at Xiaweidian has led to current arguments as to whether appropriate sedimentary environments and models were accurately proposed by previous workers.
Xiaweidian is located in the west of Beijing (Fig. 1) with exposure of well-preserved Cambrian section which can be divided into three series: Series 1 consisting of the Changping, Mantou and Maozhuang Formations, Series 2 consisting of the Xuzhuang and Zhangxia Formations, and Series 3 consisting of the Gushan, Changshan and Fengshan Formations (Mei et al., 1997; Mei, 2011; Kang et al., 2016; Ma et al., 2017; Guo et al., 2019).

The Zhangxia Formation, a part of Middle Cambrian outcrops, was firstly named in the year of 1907 by Willis and Blackwelder in Shandong province of China based on its lithological characteristics (Ni, 2017). The Zhangxia Formation at Xiaweidian is approximately 78 meters in thickness

${ }^{*}$ Corresponding author.

E-mail address: zXw_geology@163.com (X. Zhang); pangxq@cup.edu.cn (X. Pang); cjzk@cup.edu.cn (Z. Jin); eric_hu_cup@126.com (T. Hu); abdulkareem.toyin@fulokoja.edu.ng (A. Toyin); wangke8398@163.com (K. Wang). 2207-9963 (c) The Author(s) 2020.

Received January 6, 2020; revised February 22, 2020; accepted February 22, 2020; available online February 25, 2020. 


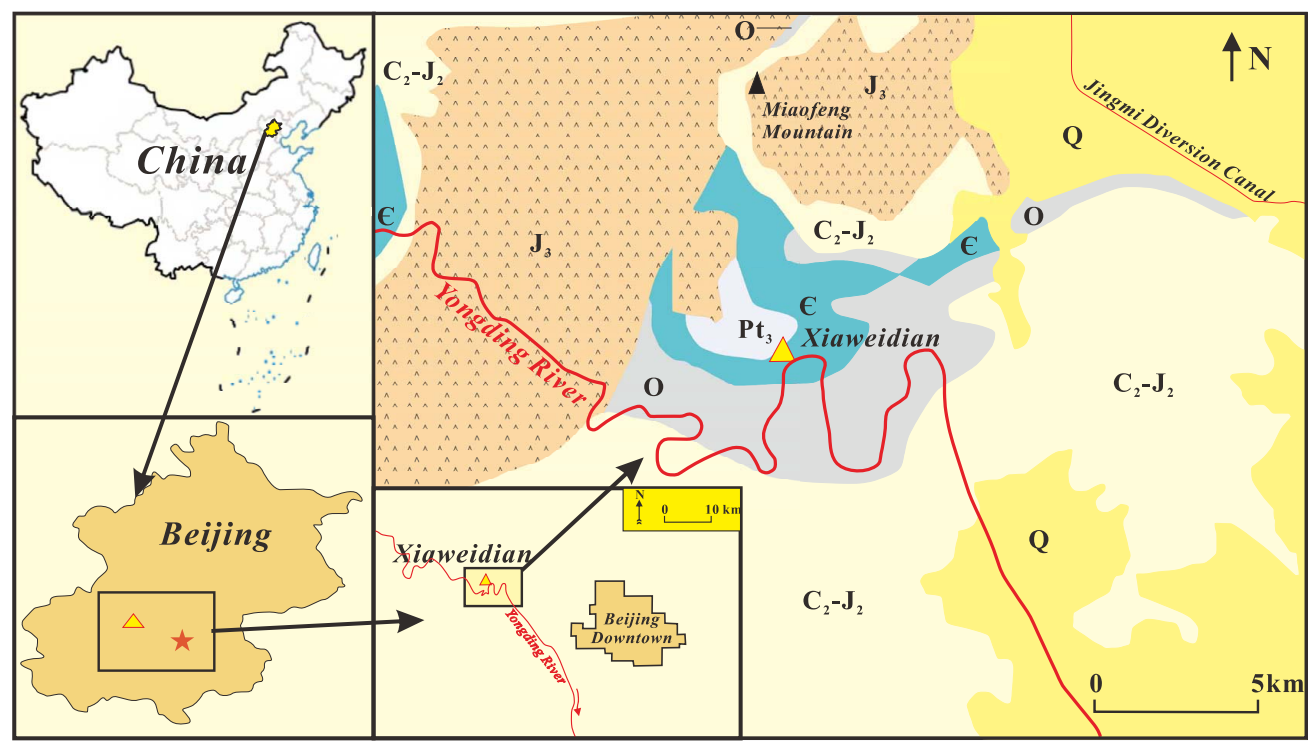

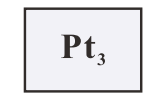

Upper Proterozoic

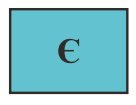

Cambrian

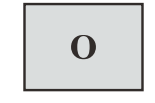

Ordovician

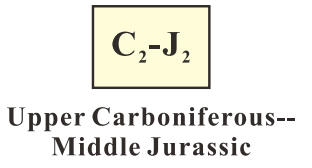

Upper Carboniferous
Middle Jurassic

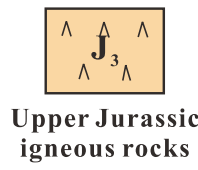

igneous rocks
Q

Quaternary

Fig. 1. Geological map showing different rock distribution and their ages exposed at Xiaweidian and its adjacent areas (adapted from Kang et al., 2016).

(Wang et al., 1990; Jing et al., 2015; Guo et al., 2019) and is divided into upper, middle and lower parts. The lower part contains four different types of rocks, including oolitic limestone, muddy limestone (or marl), calcareous mudstone and flat-pebble limestone (or flat-pebble conglomerate), while the upper and middle parts mainly contain oolitic limestones. Therefore, the lower part of this formation is representative and selected for the study of its lithology, textures, sedimentary structures, etc.

Previous related works on the Zhangxia Formation at Xiaweidian include the stratigraphic sequences of the entire Cambrian section (Zhu et al., 2009; Mei, 2011; Ma et al., 2017; $\mathrm{Ni}, 2017$ ), sedimentary environments of the Middle Cambrian formations (Zhang et al., 2009; Guo et al., 2019), features of ooids and their environmental implication (Wang et al., 1990; Ma et al., 2017), origins of flat-pebble limestones (Zhang and Wan, 1990; Jing et al., 2015) and bioherms of the Zhangxia Formation (He et al., 2012; Ma et al., 2017). And results from these studies suggested two types of carbonate platforms (i.e. carbonate marine ramp and isolated platform) as depositional environments of this formation.

Carbonate platform represents any shallow marine environment where there is accumulation of carbonate sediments (Fig. 2) (Read, 1985; Meng et al., 1997; Kiessling et al., 2003; Zampetti et al., 2004; Nichols, 2009). The ramp is divided into inner ramp, mid-ramp and outer ramp based on different wave bases (fair-weather wave base and storm wave base) (Tucker, 1985; Burchette and Wright, 1992). From inner ramp to outer ramp (seaward), the wave energy attenuates and within the inner ramp, the barrier bar sometimes develops and this results in deposition of grainstones. Hummocky cross-stratification forms on the mid-ramp due to frequent storm reworking. Carbonate mudstones are deposited on the quiet outer ramp, where infrequent storm reworking of early sedimentary beds occurs. On the isolated platforms, there are three different regions: restricted platform, carbonate bank and open platform. The presence of carbonate bank is the distinctive feature of the isolated platform (Purkis et al., 2014; Rankey et al., 2019). This carbonate bank is characterized by a fair-weather wave base, and it can be also be divided into two parts: high energy bank, which is above the fair-weather wave base with mostly grainstone deposits, and the intermittent high energy bank, which is near the fair-weather wave base and most of the deposits are essentially packstones (Jin et al., 2013; Guo et al., 2019). Furthermore, the restricted platform is located at the landward region of carbonate bank (Fig. 2). Here, seawater is restricted, thus causing a reducing and quiet environment, and contacts with clastic shallow marine is also possible. The open platform is at the seaward side of carbonate bank and mostly, it is characterized by the oxidizing condition.

Some researchers including Mei (2011), Jing et al. (2015), Kang et al. (2016), Ma et al. (2017) and Ni (2017) suggested that the Zhangxia Formation were deposited in ramp related environments. Medium or thick ooid grainstones were formed on the inner ramp. The thin ooid packstones with interbedded flat-pebble limestones were suggested to have been deposited on the mid-ramp, while the calcareous mudstones and muddy limestones were believed to be associated with the outer ramp. Other contributions from Wang et al. (1990), Zhang et al. (2009) and Guo et al. (2019) on the Zhangxia Formation indicated its sedimentation on the isolated platform and proposed the formation of oolitic limestones was related 


\section{Ramp}

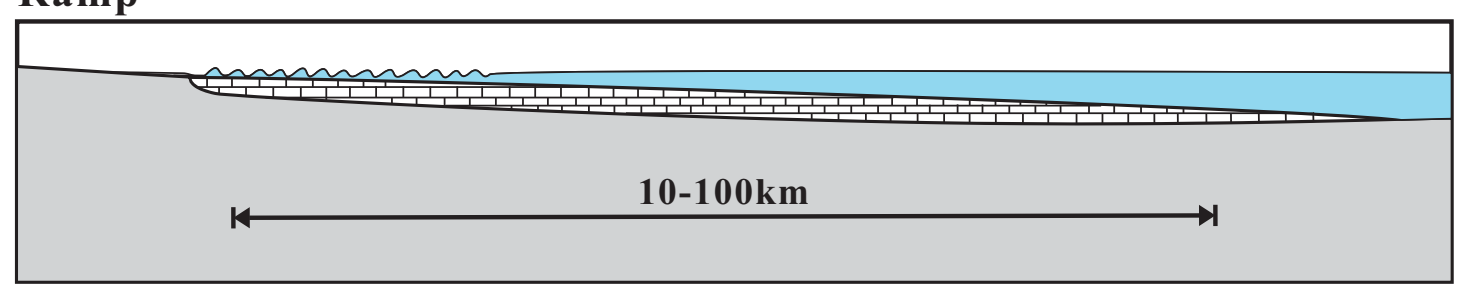

Isolated platform

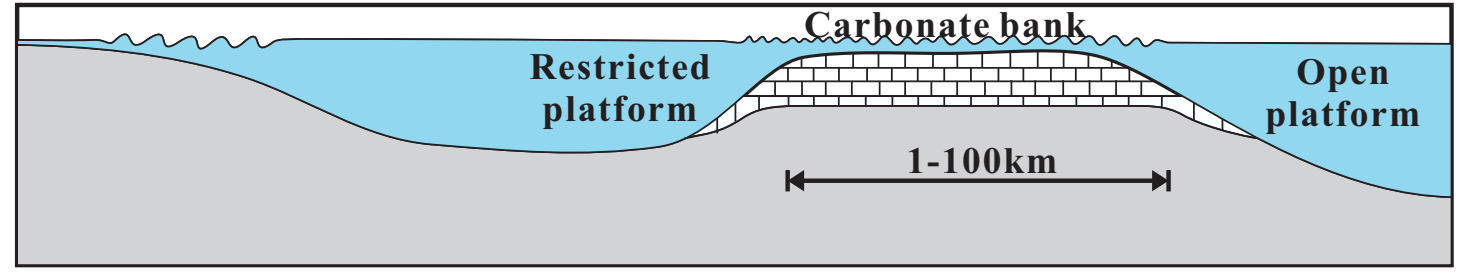

Fig. 2. Different forms of carbonate platforms within a shallow marine environment (modified from Nichols, 2009). Ramp and isolated platform are the major carbonate platform types and can be further divided based on the wave energy.

to the carbonate bank. The calcareous mudstones and muddy limestones according to Zhang et al. (2009) has been related to deposits on open platform. But in a study by Guo et al. (2019), it was concluded that the muddy limestones of the Zhangxia Formation were deposited on a restricted platform, while the mudstones were formed in the adjacent areas.

In this study, we provide more evidence to ascertain the sedimentary environments of the Lower Zhangxia Formation by describing and analyzing characteristics of its rocks according to outcrops, thin sections and results of scanning electron microscopy (SEM) and electron dispersive spectrometry (EDS), and finally interpreting sedimentary environments of this formation.

\section{Methods}

Two basic methods were employed in this study: field work and laboratory analyses. During the field work exercise, outcrops believed to be part of Lower Zhangxia Formation at Xiaweidian were mapped. Lithological sections were carefully studied and information based on sedimentological, structural and paleontological characteristics were appropriately recorded. Each exposed section was measured and bed thicknesses were recorded. Fresh outcrop samples were collected and kept in a clean polythene bag after being labelled appropriately. The samples were taken to laboratories of China University of Petroleum-Beijing for further analysis.

For the laboratory analyses, petrographic thin sections were prepared at the State Key Laboratory of Petroleum Resources and Prospecting, China University of Petroleum-Beijing. In addition, SEM and EDS were carried out at the Microstructure Laboratory for Energy and Materials of China University of Petroleum-Beijing. These analyses were carried out in order to obtain a better view of microscopic features of the sampled rocks. About 20 rock samples comprising mudstone, muddy limestone and oolitic limestone samples were selected for thin sectioning. Out of these selected samples, 5 samples were specifically selected for further analyses, i.e. SEM and EDS. SEM has been used to analyze surface physical features of rock samples on micro scales (Crawford and Quinn, 2017). There are two kinds of images that could made from SEM: sScattered electron (SE) and back-scattered electron (BSE) image, and both are obtained from detecting different electrons (Roane and Pepper, 2009). Moreover, the EDS analysis is a method used to detect the characteristic X-ray of rock samples, and it is a simple and convenient method to detect various elements in different appointed areas within samples (Tanaka et al., 2018).

\section{Lithological description}

Petrographic features of the Zhangxia Formation, such as rock type, color, textures and structures, are described from macroscopic to microscopic scales based on field observations of the outcrops and laboratory analysis of hand specimens and thin sections using light microscopy and SEM. Bed by bed logging was also done with the recording of individual bed thickness. The various rock units are described in detail (Fig. $3)$.

\subsection{Oolitic limestone}

Oolitic limestone is the most common type in the Zhangxia Formation (Fig. 4). They occur dominantly in massive form and they are gray in color. Individual bed thickness varies: beds of lower part are less than $1 \mathrm{~m}$ thick, while those in the middle and upper parts are more than $1.5 \mathrm{~m}$ thick. Microscopic view of oolitic limestone as obtained in this work is shown in Fig. 5. Major components of these rocks are ooids and limemuds (Figs. 5 and 6). Most of the ooids are less than $1 \mathrm{~mm}$ in diameter, and are varied from fine- to medium-grained (Fig. 5). 


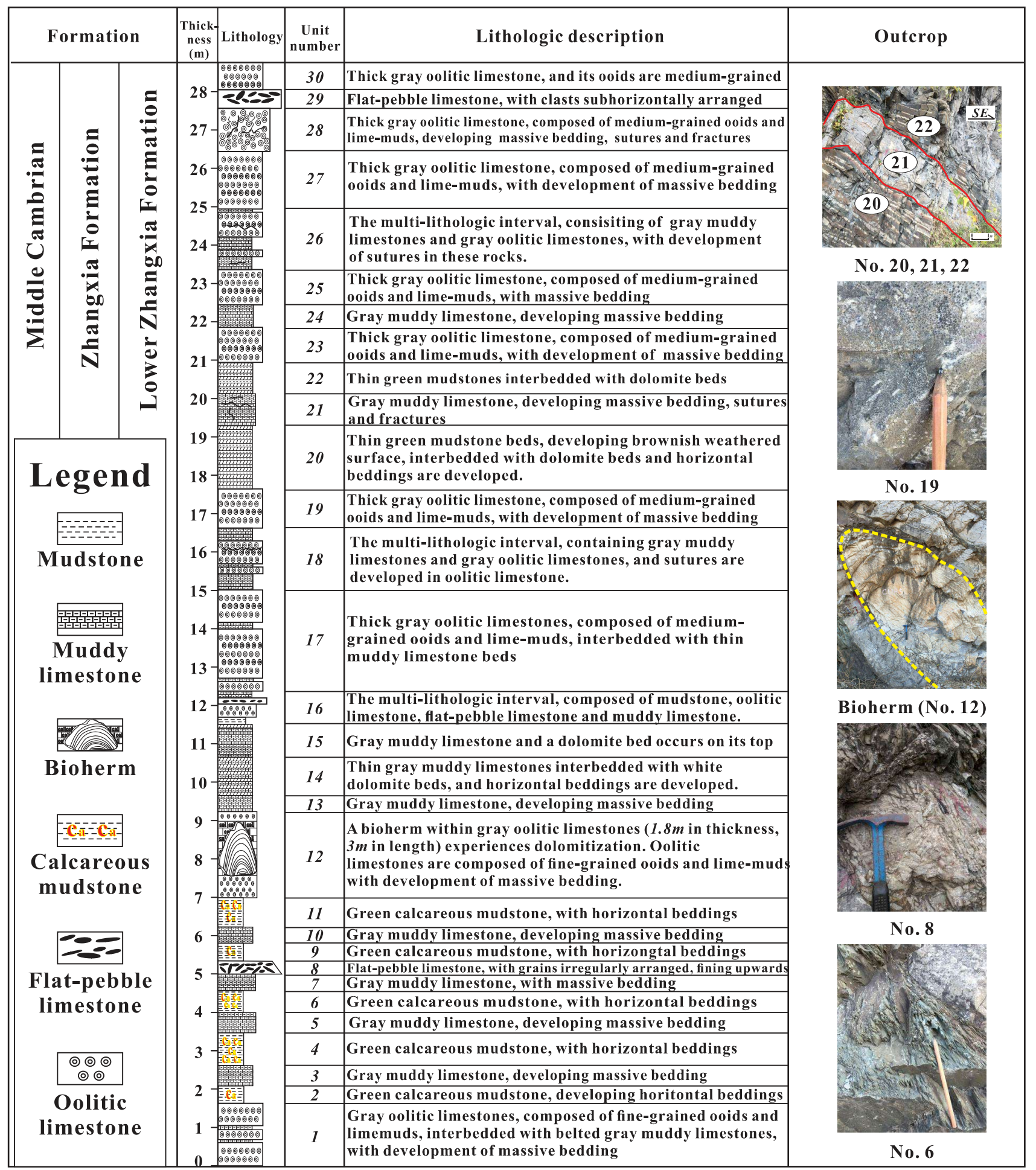

Fig. 3. Lithostratigraphic section of the Lower Zhangxia Formation exposed at Xiaweidian, which is approximately $29 \mathrm{~m}$ in thickness and is divided into 30 units based on the lithological. 


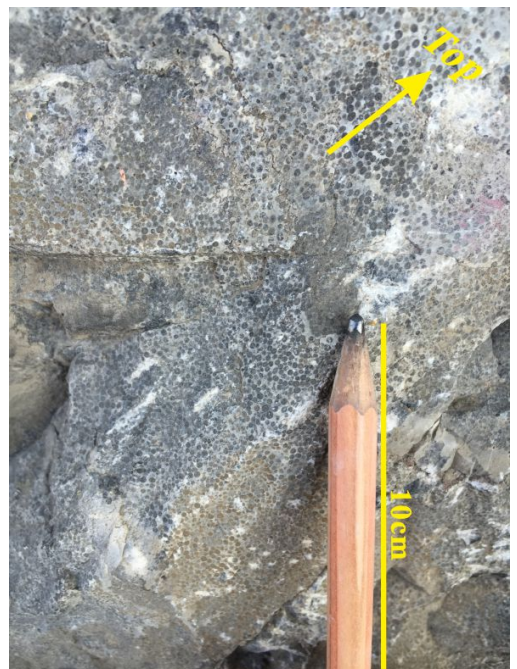

Fig. 4. Oolitic limestone of the Lower Zhangxia Formation containing approximately $80 \%$ medium-sized ooids.

Moreover, the SE image shows features of ooids (Fig. 6). Within the ooid is a nucleus filled with detrital material which is seemly a calcite grain with well-defined crystal shape, as shown in the upper-left ooid in Fig. 6. Although concentric lamellar pattern of coats is not present within some ooids, this pattern is usually traversed by a well-developed fabric of radially arranged calcite fibers in ancient ooids (Bathurst, 1972; Adams and Mackenzie, 1998; Adams et al., 2017). Such well-developed radial structure can be also discerned under cross-polarized light as shown in Fig. 5a. It is also noteworthy that some ooids have undergone partial recrystallization, and this has resulted into loss of their original shape (Fig. 5b). Besides, nearly all ooids are smaller than $1 \mathrm{~mm}$ in diameter and they are well-sorted with roughly spherical shapes.

The matrix within the oolitic limestones are dominantly made up of lime-muds and they appear dark under planepolarized light (Fig. 5b). Lime-muds generally composed of small pieces of calcite or aragonite with their sizes usually less than $20 \mu \mathrm{m}$. Because of relatively high content of lime-muds ( $>10 \%$ in grain-supported limestones), these oolitic limestones in the Zhangxia Formation can also be defined as packstones in Dunham's classification (1962).

\subsection{Muddy limestone}

Muddy limestone (marl) is defined by its mineral composition, which consist briefly of a mixture of clay and finegrained calcium carbonate in varying proportions between 35 and $65 \%$ (Scholle and Ulmer, 2003). This type of rock is also transitional between mudstone and micritic limestone. Hence, it cannot be named as "carbonate mudstone" in Dunham's classification (1962), which is the pure carbonate rock without clastic mud.

Muddy limestones mainly occur at lower part of the Zhangxia Formation with thicknesses ranging from $20 \mathrm{~cm}$ to 2 $\mathrm{m}$, and are in contact conformably with adjacent beds (see Fig. 3 ). These muddy limestones are gray in color and are occurring in massive forms. Sutures and fractures are also well developed. At some points, some of rocks have undergone processes of weathering thereby producing brownish weathered surfaces (Fig. 7).

Lime-muds, as components of muddy limestones, are dominantly made up of calcites which are also the "matrix" of oolitic limestones, because their diameters are totally less than $0.02 \mathrm{~mm}$ (Figs. 8, 9a and 10) (Dunham, 1962). In this current study, lime-muds in analyzed samples did not develop welldefined crystal shapes. Some of them have been broken and possessed sharp edges (Fig. 10).

Moreover, existence of clays could also be used as a distinctive mark of muddy limestones. These clays are in form of striped clusters, dark and easily fractured. In-situ stress during burial could thereby result in belted clays developing fractures, while few fractures developed in the adjacent limemuds as shown in Fig. 8a.

A few medium-grained calcites $(0.063$ to $2 \mathrm{~mm}$ in diameter) were also noticed within the muddy limestones (Fig.
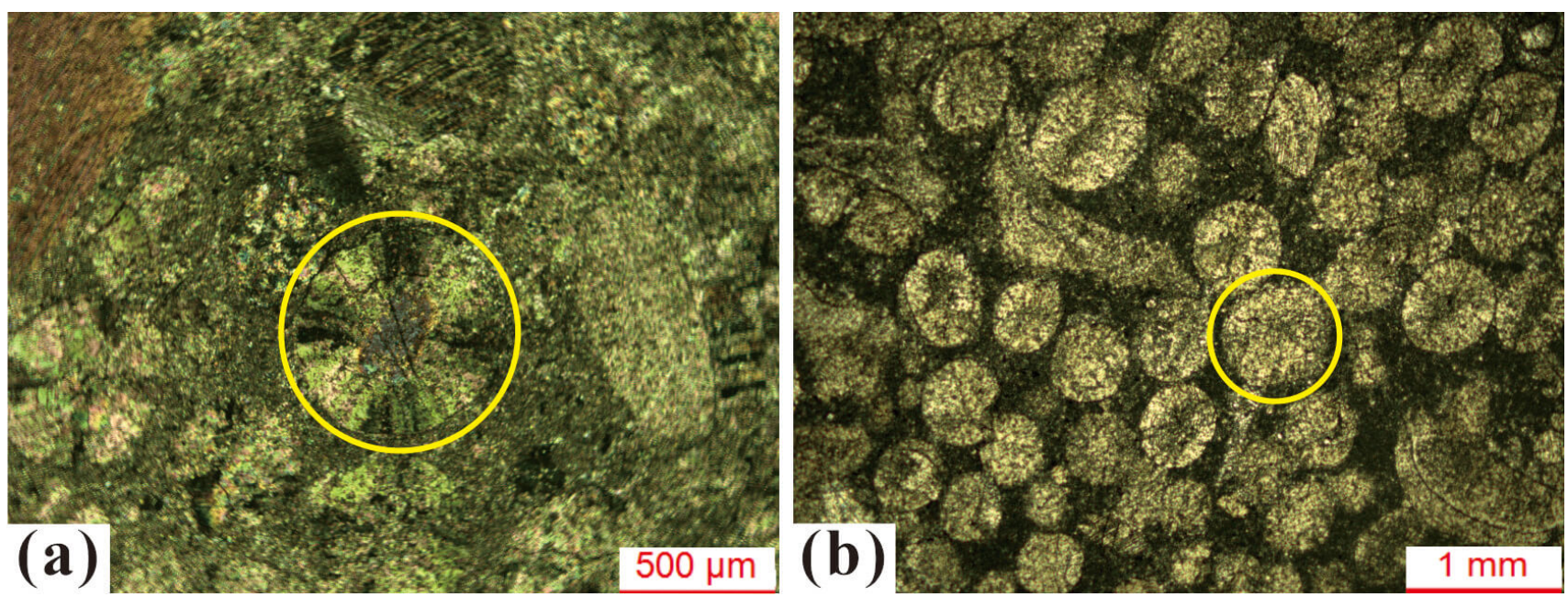

Fig. 5. Microscopic images of oolitic limestones in the Lower Zhangxia Formation. (a) Well-developed radial structure of an ooid in the center of this image, unstained, cross-polarized light. (b) Recrystallization of an ooid marked by the yellow circle, unstained, plane-polarized light. 

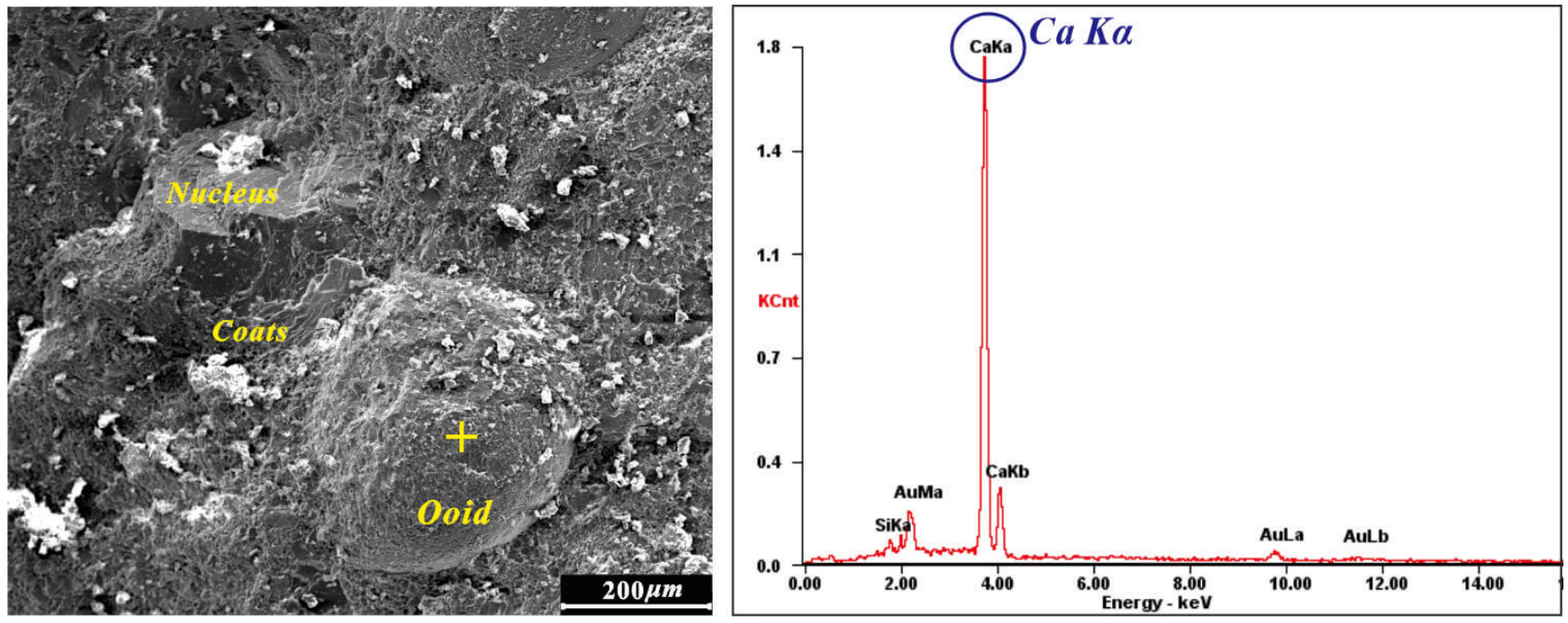

Fig. 6. SEM SE image and EDS spectrum of the ooid (indicated by a yellow cross). The SE image shows the size and surface features of ooids. In the EDS spectrum, $\mathrm{Ca} \mathrm{K} \alpha$ is dominant. Au peaks are due to the gold-coating.

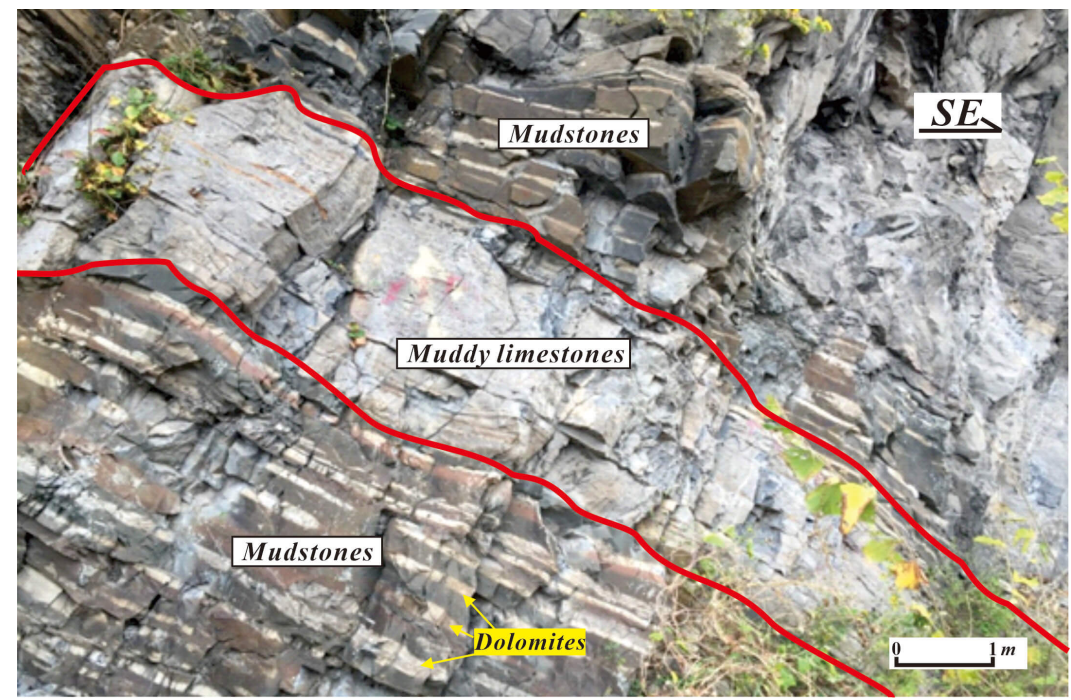

Fig. 7. Outcrop of muddy limestones and mudstones in the Lower Zhangxia Formation. The middle gray beds are muddy limestones, with well-developed horizontal beddings, sutures and fractures, while adjacent beds are thin green mudstones interbedded with dolomites formed by dolomization of muddy limestones. The brownish outcrops of parallel mudstone beds were caused by weathering.
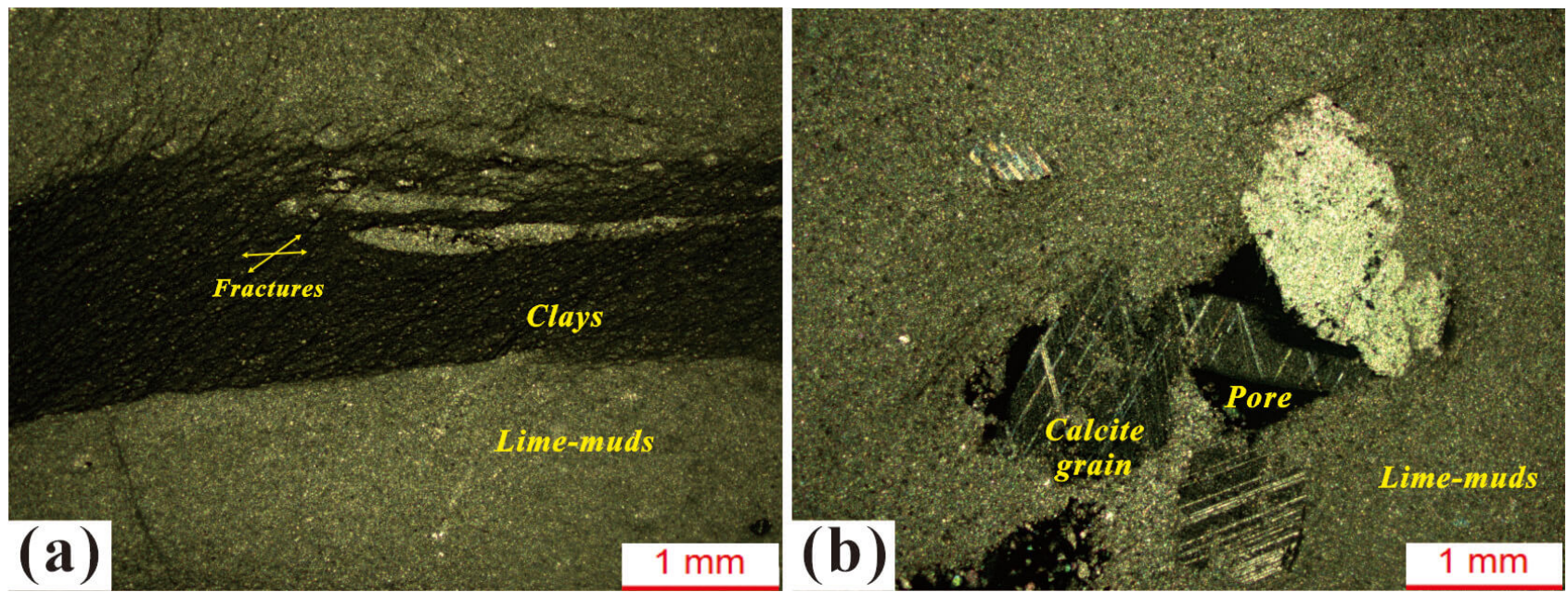

Fig. 8. Muddy limestones in the Lower Zhangxia Formation. (a) Muddy limestone with lime-muds and clays that developed oblique fractures, unstained, plane-polarized light. (b) Muddy limestone with medium-grained calcites showing perfect cleavages, unstained, cross-polarized light. 

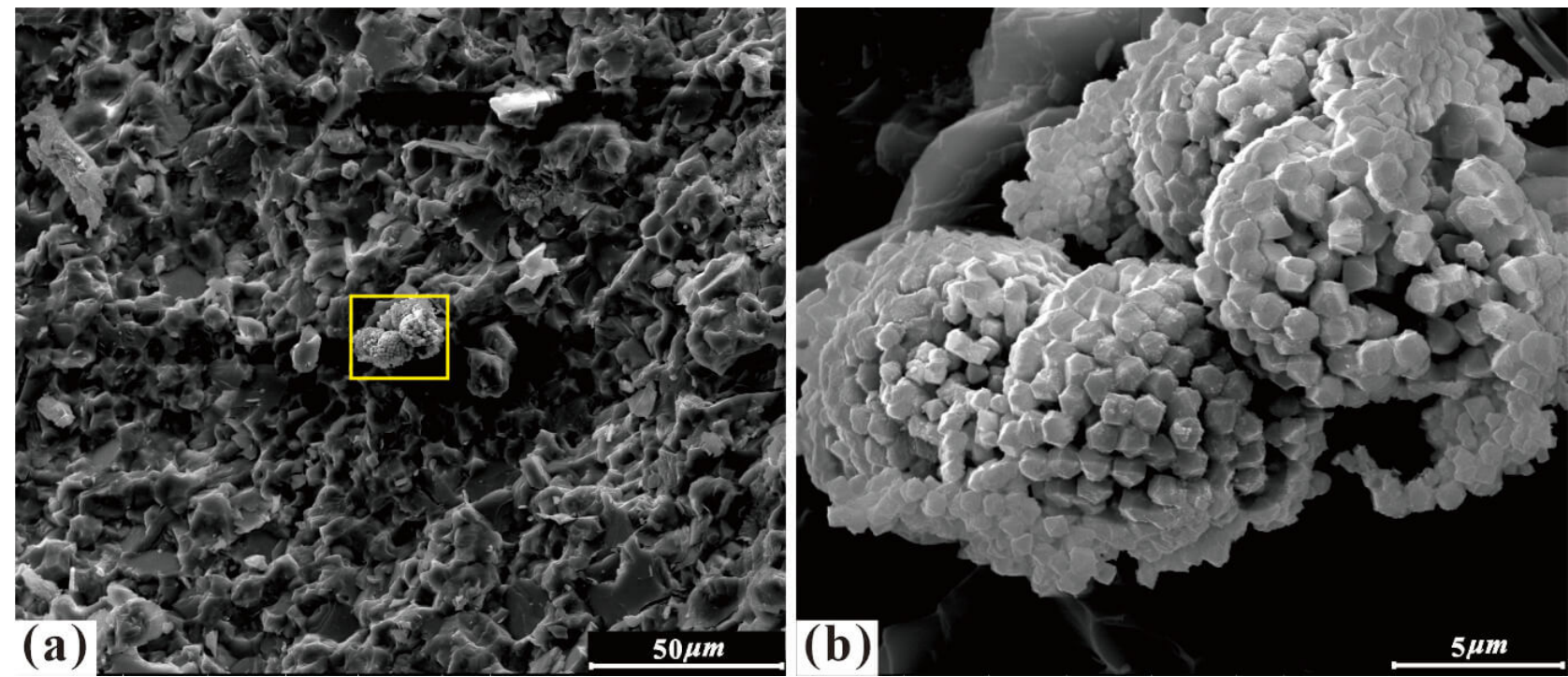

Fig. 9. SEM SE images of the muddy limestone (a) and framboidal pyrite aggregates (b) in the Lower Zhangxia Formation.
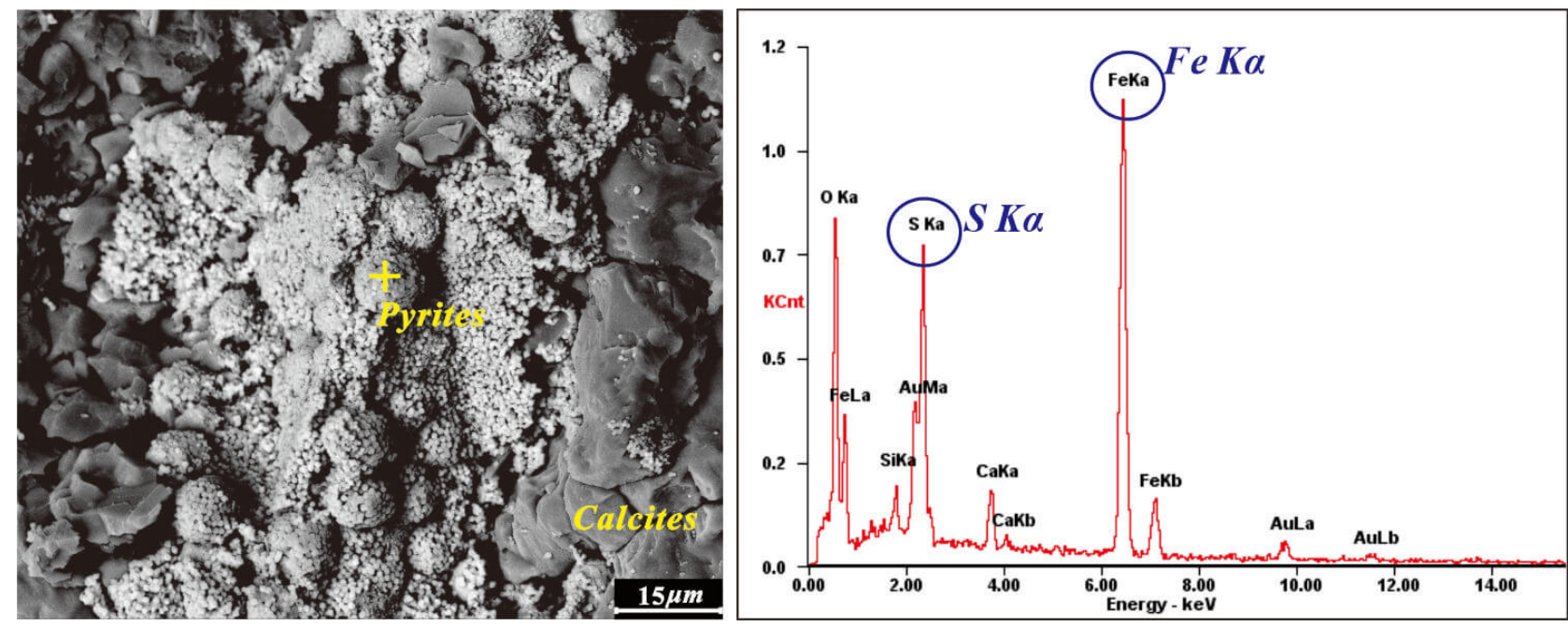

Fig. 10. SEM BSE image of framboidal pyrite aggregates in the muddy limestone of the Lower Zhangxia Formation and EDS spectrum of the pyrites (indicated by a yellow cross). The EDS spectrum indicates that the framboidal pyrite aggregates are mixed with some carbonates and clay silicates.

$8 \mathrm{~b})$, and these calcites possess oblique cleavages during observation under the cross-polarized light (Fig. 8b). The calcites are poor-rounded without any significant biological structure. Thus, it could be believed that these calcites might be broken grains of other types of limestones.

Furthermore, dolomite replacement of micrites occurs in some muddy limestones. This type of dolomitization can be recognized in outcrops at Xiaweidian, although the dolomite beds are thin and interbedded with mudstones (Fig. 7).

Further mineralization within the muddy limestones produced pyrites (Figs. 9 and 10). Pyrite normally crystallizes in cubic system and has a brass-yellow color (Haldar, 2013).

The SE images of muddy limestone show clearly pyrite minerals with well-developed crystal shapes and their sizes are smaller than $2 \mu \mathrm{m}$ in diameter (Fig. 9b). These pyrite minerals also clustered together forming spherical aggregates (Figs. 9 and 10). The EDS spectrum in Fig. 10 shows the elementary composition of the pyrite, which is pointed in Fig. 10. As shown in this diagram, both $\mathrm{Fe}$ and $\mathrm{S}$ are dominant elements having higher proportions than others.

\subsection{Calcareous mudstone}

Generally, clay content in mudstone is often not less than $33 \%$, and sizes of clay minerals are usually within the range of about $0.0039 \mathrm{~mm}$ (Haldar, 2013). However, in the Lower Zhangxia Formation, the clay content of mudstones is more than $50 \%$ with calcite content ranging from $25 \%$ to $50 \%$ (Mei, 2011; Ni, 2017; Guo et al., 2019), so this type of mudstone can be named as "calcareous mudstone" (Feng, 2004). The nature of occurrence of the calcareous mudstone is shown in Fig. 11. They are green in color, with thickness of not more than $1.5 \mathrm{~m}$. This rock type occurs only at the base of this studied formation. Horizontal and massive bedding are the most com- 

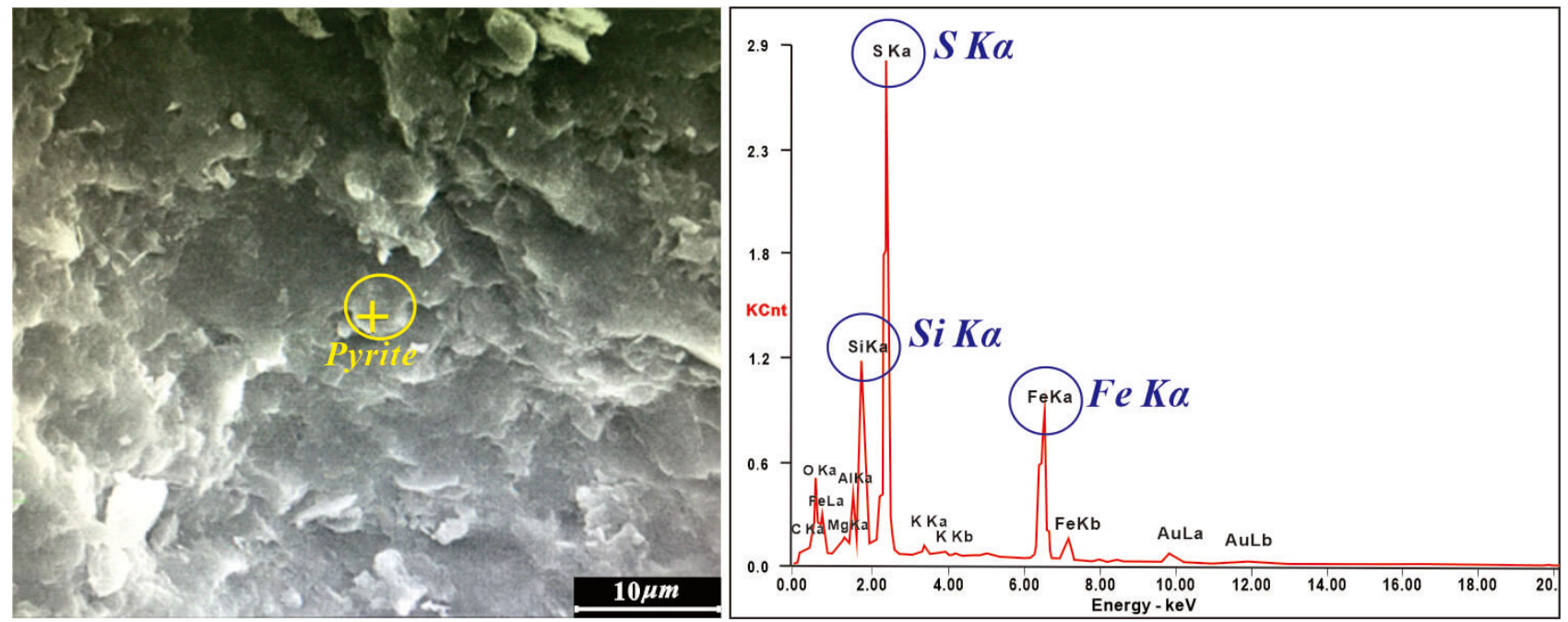

Fig. 12. SEM SE image of the mudstone and EDS spectrum showing the major elements of pyrite (yellow cross). The EDS spectrum shows that the phase identified has significant amount of $\mathrm{S} \mathrm{K} \alpha$ and $\mathrm{Fe} \mathrm{K} \alpha$, indicating the phase is pyrite. The $\mathrm{Si} \mathrm{K} \alpha$ peak is from the surrounding silicate minerals in mudstone.

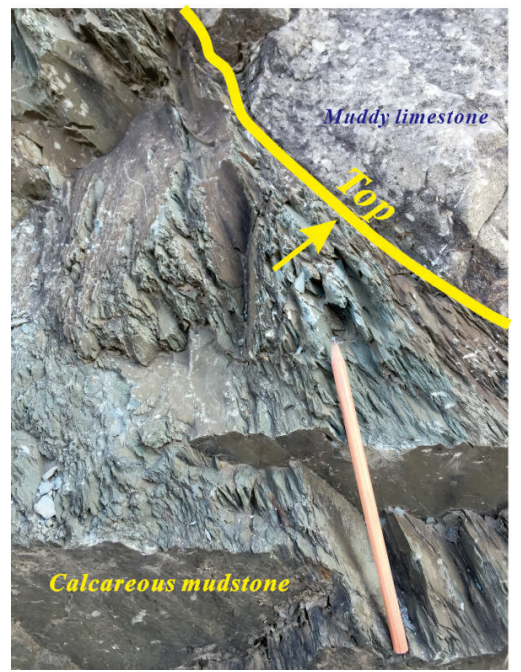

Fig. 11. Calcareous mudstones in the Lower Zhangxia Formation Note the greenish coloration and horizontal beddings of this rock. The pencil is $15 \mathrm{~cm}$ long.

mon structural features of this rock.

Furthermore, clay minerals are the major constituents of this type of rock. The notable ones include illites, chlorites, kaolinites and smectites commonly. It is highly impossible to observe their features and identify them through petrographic thin sections. But SE image can help the identification of these common clay minerals using their shapes and the nature of aggregates formed by these minerals in calcareous mudstones. Both smectite and chlorite crystallize in monoclinic system $(<1 \mu \mathrm{m})$ and can be explored by electron microscope. Chlorites are often formed through regional metamorphic processes at lower temperatures, and their occurrences in sedimentary rocks are usually uncommon (Haldar, 2013; Barker, 2014). Kaolinite crystallizes in triclinic system, forming hexagonalprismatic clusters, and could also be recognized easily under electron microscope. Illites always form mixed-layer clusters

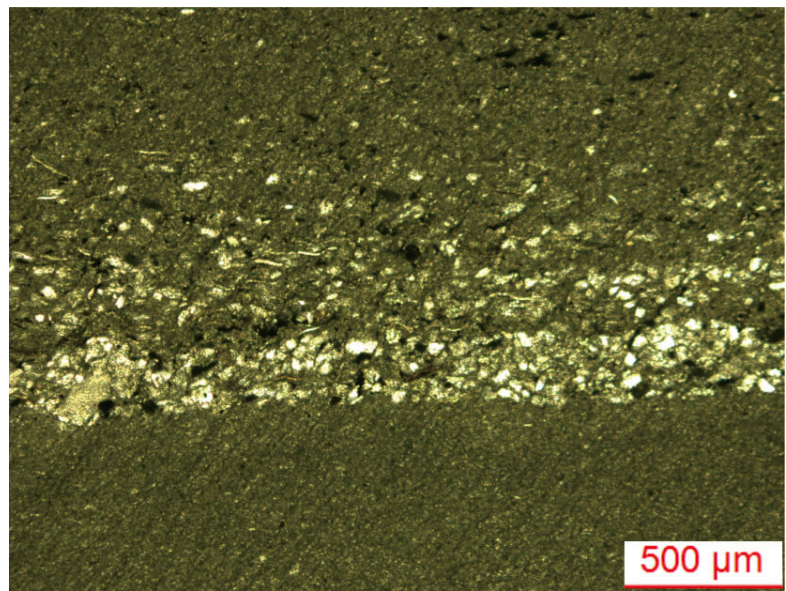

Fig. 13. Calcareous mudstone, unstained, plane-polarized light. Silts, moderately to well sorted, occur in the mudstone.

with disordered smectite layers, and are mainly derived from processes of surface rock weathering, illitization of feldspar and muscovite, as well as illitization of kaolinite and smectite. Under the image of our sample, Platy kaolinites cannot be observed apparently, while smectites are observable and likely to be the major clay minerals in the studied mudstones (Fig. 12). Relatively high amount of $\mathrm{Si}$ is also noticed in the spectrum and this may have been formed as a result of silicious coat outside pyrite which often appears in mudstone.

Moreover, silts which are nearly pure quarts occur as belted clusters. Their sizes are less than $0.1 \mathrm{~mm}$ in diameter. Fig. 13 shows these quart-rich silts identified in this study. They are moderately to well sorted and are irregularly arranged.

\subsection{Flat-pebble limestones}

Flat-pebble limestone is also known as flat-pebble conglomerate. This rock type is very common in Cambrian strata and has been reported in many places such as North America 

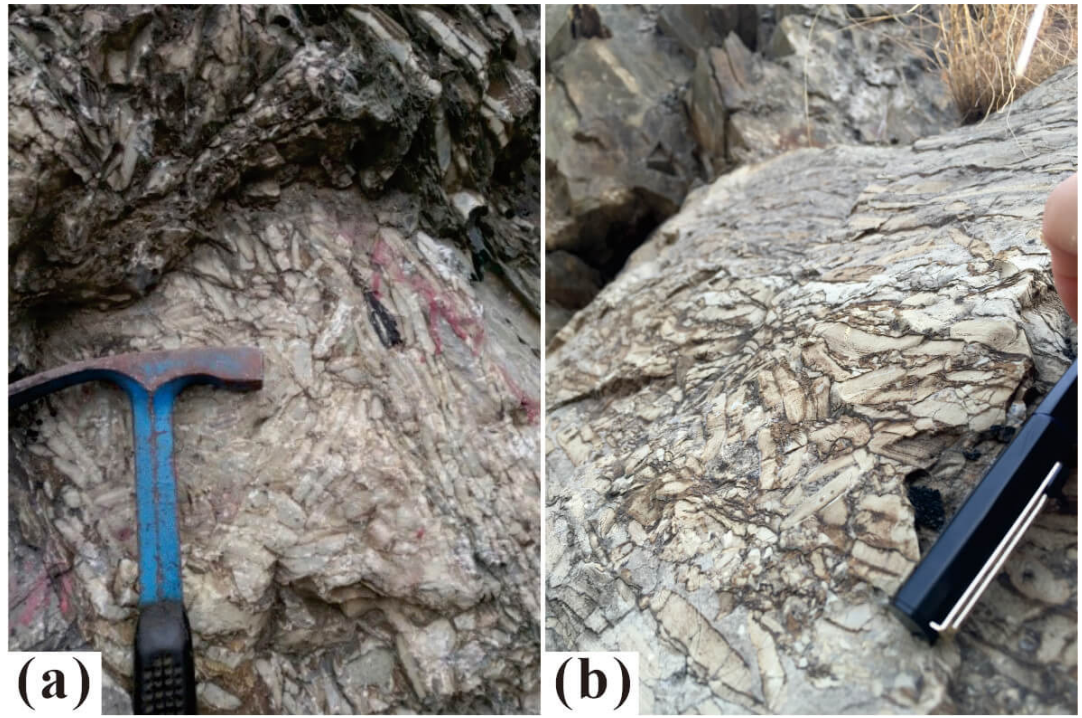

Fig. 14. Flat-pebble limestone in the Lower Zhangxia Formation at Xiaweidian. Thicknesses of flat-pebble limestone beds are less than half meters, and their fabrics range from matrix (a) to clast (b) supported, and their intraclasts are distributed randomly or slightly horizontally, especially in beds with large amounts of clasts. The hammer is $33 \mathrm{~cm}$ long and cap is $5 \mathrm{~cm}$ long.

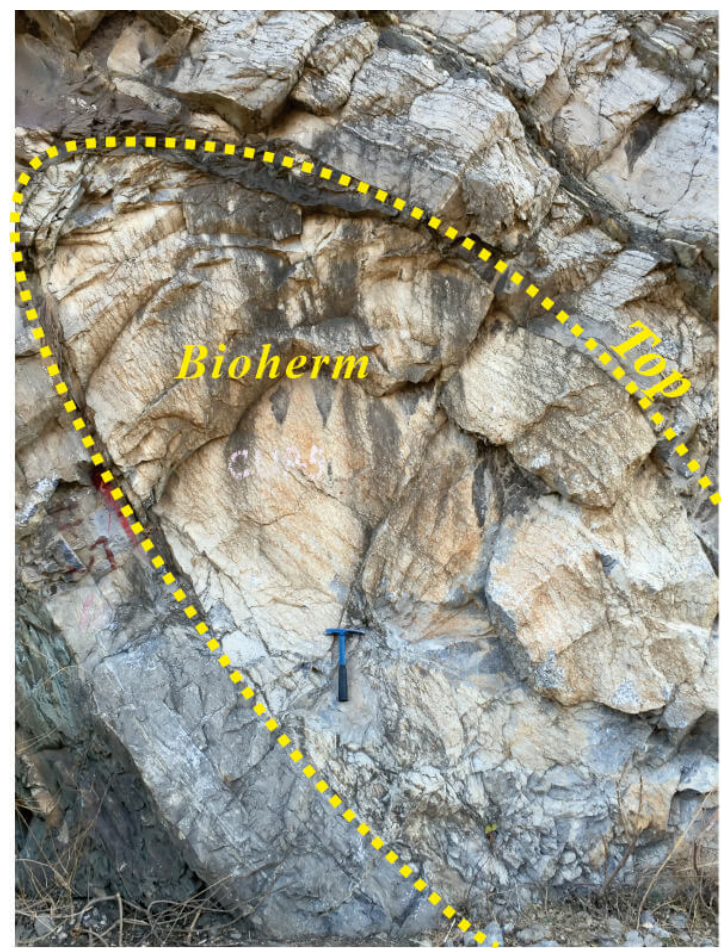

Fig. 15. A bioherm in the Lower Zhangxia Formation at Xiaweidian Note the plano-convex structure of this bioherm. Its size is $1.8 \mathrm{~m}$ in thickness and $3 \mathrm{~m}$ in length. The hammer is $33 \mathrm{~cm}$ long.

(Sepkoski, 1982; Myrow et al., 2004) and China (Zhang and Wan, 1990; Yu et al., 2015).

Our field observations indicate that beds of both white and brown flat-pebble limestones are present in our study area. They are conformably in contact with adjacent beds and their thicknesses also vary from about $10 \mathrm{~cm}$ to nearly half meter. Fabrics nature of these beds ranges from clast to matrix supported (Fig. 14). Their flat-pebble clasts possess coarse-grain texture and have similar composition to muddy limestones. These features are not related to the position of these beds and lithological characteristics of adjacent rocks. Even adjacent to calcareous mudstones, these beds also contain coarse-sized clasts (Fig. 3). Degree of rounding is highly variable from well-rounded to angular clasts, although in some cases they show partial brittle deformation. Intraclasts of the thinner beds tend to be smaller and flat-lying, whereas in thicker beds, intraclasts are larger and they often lie at high angles to bedding (Figs. 3 and 14).

\subsection{Bioherm}

A bioherm occurs inside an oolitic limestone interval, causing observable lateral thickness variation in its outcrop (Fig. 15). This bioherm can best be described as the plano-convex structure with a flat base and arched upper surface. In this work, the bioherm has been estimated to be up to $1.8 \mathrm{~m}$ thick, and almost $3 \mathrm{~m}$ in length. In some regions, there are numerous Cambrian bioherms occurring in a single stratigraphic horizon, typically separated from one another by about 3 to $5 \mathrm{~m}$ of inter-reef sediments (James and Debrenne, 1980). But in the Lower Zhangxia Formation at Xiaweidian, only one bioherm was discovered. Mainly Cryptomonas, bounded by carbonate sediments, composed of this bioherm (He et al., 2012).

\section{Interpretation}

Detailed observations from the field and different analytical techniques combined in this present study have broaden our knowledge which has usefully improved understanding on depositional environments of the Lower Zhangxia Formation exposed at Xiaweidian. These will be helpful to solve current issues regarding the proposed models on the Zhangxia Formation by previous workers. New insights into formation mechanisms of these rocks have been provided and also new 
evidence which will thereby better help in making appropriate interpretations on this topic has also been presented.

\subsection{Oolitic limestone}

Generally, oolitic limestones are thought to be products from high energy environments such as the inner ramp and carbonate bank. But in fact, in some other studies, scholars have reported the presence of oolitic limestones in environment with relatively low energy and this type of environment has been referred to as intermittent high energy environments (Jin et al., 2013; Guo et al., 2019). Similarly, in this current study, intermittent high energy environment could be also viewed as the depositional environment of oolitic limestones in the Lower Zhangxia Formation.

Composition of oolitic limestones can help predict the nature and energy level of their depositional environment. When seawater is highly turbulent, lime-muds are likely to be washed away and not preserved as matrix among ooids. In this case, pores are created and they become favorable 'habitats' for the cementation of spars. On the contrary, if the energy of seawater is relatively low, lime-muds will remain among ooids. Based on the nature of fillings, especially by lime-muds within the oolitic limestones of the Lower Zhangxia Formation (Fig. 5), it is reasonable to infer that the depositional environment of the studied oolitic limestones was not as turbulent as areas above normal wave base.

Features of ooids can also be used to deduce the nature of facie. Based on the composition of ooid coats, arrangement of coat minerals, and effect of organic matters during ooid formation, Wang et al. (1990) classified ooids into 4 types: radial ooids, radial-concentric ooids, polyooids and organic material-rich ooids. These authors further affirmed that radial ooids, polyooids and organic material-rich ooids were formed in relatively low wave energy environments while radialconcentric ooids were generated in a high energy environment and are cemented by spars. In our findings, ooids in the Lower Zhangxia Formation mainly possess well-developed radial structure (Fig. 5a), and this support our conclusion and interpretation made in the previous paragraph.

In addition, the size and shape of carbonate particles are capable of providing information on the nature of their depositional environments and transportation history (Bathurst, 1975; Davies et al., 1978; Sumner and Grotzinger, 1993; Nichols, 2009; Summons et al., 2013; Trower et al., 2017). It was observed from our thin sections that the studied ooids are less than $1 \mathrm{~mm}$ in diameter and are well sorted (Fig. 5). This also suggests that the energy of formation of the studied sediments was relatively low.

\subsection{Muddy limestone \& calcareous mudstone}

Composition of the muddy limestone offers new insights into their depositional environments. In comparison with the carbonate mudstones, muddy limestones contain higher clay content thus indicating probable influence by clastic inputs at the source area (Fig. 8a). In addition, the medium-or coarse- grained calcites (Fig. 8b) within muddy limestones are also of great importance. No biological feature exists in these grains, suggesting they are not likely to be components from broken parts of marine fossils, such as crinoids. Their broken and irregular shape and existence of large interparticle pores (Fig. $8 b$ ) indicate rapid deposition through storm transportation and probable input of carbonate sediments from adjacent areas. Therefore, the presence of clastic and carbonate particles inside muddy limestones could reflect possible deposition within a transitional environment.

As to the calcareous mudstones, their composition is also helpful to reflect their formation conditions. The belted clusters of quarts which are moderately to well sorted and with irregular orientation (Fig. 13) indicate significant influence from terrigenous materials. This also indicates that mudstones were formed in areas not far away from land and could receive terrigenous inputs.

In addition to their composition, interpretations made on depositional environments of muddy limestones and calcareous mudstones could also be on the basis of evidence from chemical features of these environments. And less emphasis should be placed on their physical features, such as wave energy level, which are similar in the common deposition regions of muddy limestones and mudstones.

Pyrite is used as an ideal indicator of the chemical condition of its formation since it is unstable and easily transforms into sulfate mineral during oxidation processes (Chambers et al., 2001).

Thus, the occurrences of pyrites in both muddy limestones and mudstones (Figs. 9, 10 and 12) indicate these rocks were formed in reducing environments.

\subsection{Flat-pebble limestone}

The interpretation of flat-pebble limestone beds requires careful analysis of their features and sedimentological context (Myrow et al., 2004). Generally, submarine cementation or hardground formation was a necessary step in the formation of flat pebbles, given that subaerial diagenetic processes were not responsible for lithification of the earlier carbonate beds. Then these earlier beds were reworked by the storm in successive processes of breaking in situ, (transportation) and cementation. In the Lower Zhangxia Formation at Xiaweidian, although these flat-pebble limestones are adjacent to different types of rocks, they all have similar composition to muddy limestones, indicating the close relations between the formation of muddy limestones and flat-pebble limestones. In other words, "earlier beds" of flat-pebble limestones could also be the formation basis of muddy limestones. Therefore, it could be inferred that flat-pebble limestones and muddy limestones were formed in the same environment which was also below the fair-weather wave base.

\subsection{Depositional model}

Features identified in the studied rocks combined with laboratory results have provided us useful insights as to their 
depositional conditions and environments. Using these and making emphasis from other previous works (e.g., Wang et al., 1990; Feng, 2004; Guo et al., 2019), depositional model of the Lower Zhangxia Formation as shown in Fig. 16 could be better explained as follows.

This model contains two parts, clastic marine and isolated platform (Jin et al., 2013). Gradual transition from clastic to carbonate environments on the shelf was basically emphasized.

In the clastic marine, there are four subfacies: supratidal flat, intertidal flat, subtidal flat and shallow marine facies. This region is composed of clastic rocks (mudstone, siltstone, and sandstone), and is close to the land area. This makes it easier receiving input of continental sources.

The isolated platform is one form of carbonate platform, and it is divided into three parts: restricted platform, bank and open platform. Both shallow marine and restricted platform are below the fair-weather base and are the "bridge" linking the clastic and carbonate environments. In the Lower Zhangxia Formation, shallow marine, restricted platform and carbonate bank are the reasonable depositional areas for the studied rocks.

\subsubsection{Carbonate bank}

Carbonate banks in the shallow marine surrounded on all sides by deeper water are commonly sites of carbonate sedimentation because there is no source of terrigenous detritus (Nichols, 2009). Facies on carbonate bank have been characterized by several authors based on the energy level of wave transportation, i.e. high energy and intermittent high energy bank (Jin et al., 2013; Guo et al., 2019). The bank above fair-weather wave base is persistently turbulent because of high energy and mostly contains grain limestones with the cementation of spars, while intermittent high energy bank is the region near normal wave base and is occasionally less turbulent compared to that above the fair-weather wave base. On the intermittent high energy bank, there is higher content of lime-muds in addition to grains of limestones due to the relatively lower energy of seawater.

Evidence from lime-mud content and ooid features in the studied oolitic limestones of the Lower Zhangxia Formation indicates that these rocks were formed on intermittent high energy bank. In addition, presence of bioherm within the limestone also supports this conclusion (He et al., 2012).

\subsubsection{Restricted platform}

Both restricted and open platform, below fair-weather wave base, are the low energy environments, indicating muddy limestones can be formed in both environments and their differentiation would be difficult by only analyzing their physical features.

However, chemical characteristics have been proven to be a useful tool in differentiating these two depositional environments of limestones. Water circulation on restricted platform is limited by geographic conditions, and thus results in the increasing salinity of water and formation of a reducing environment (Hu et al., 2018). On the contrary, open platform is actually similar to normal carbonate shallow marine, and here, circulation of seawater is unrestricted. Therefore, rocks deposited here will be exposed to probable oxidizing condition.

In the Lower Zhangxia Formation, the occurrences of pyrites within the muddy limestones are the indication of reducing environmental condition during the sediments' formation (Figs. 9 and 10). In addition, formation of the muddy limestones could be associated with restricted platform which is transitional, receiving terrestrial inputs from adjacent land areas and also receiving larger carbonate particles from close-by marine areas (Fig. 8a). If they had been deposited on the open platform, these terrestrial inputs would have been fairly difficult to be transported over the bank.

Mid- or outer ramp has also been considered as the depositional site of muddy limestones (Jing et al., 2015; Kang et al., 2016; Ni, 2017), but such assumption might not be totally justified because ramp is a pure carbonate environment. Generally speaking, restricted platform could be more appropriate depositional environment for the formation of muddy limestones in the Lower Zhangxia Formation than open platform and ramp.

As pointed out earlier, flat-pebble limestones are storm deposits that were formed below the fair-weather wave base and also formed in the same environment of muddy limestones. Consequently, formation of this rock can also be interpreted as a result of sedimentation on restricted platform.

\subsubsection{Shallow marine mudstone}

Mudstones are the dominant rocks spreading broadly and always formed in low wave energy environments. Different opinions as to whether this rock was formed on the outer ramp or the abyssal basin still exist (Mei, 2011; Jing et al., 2015; Kang et al., 2016; Ma et al., 2017; Ni, 2017).

Outer ramp and abyssal basin are far from land. If there had been mudstones formed in these environments, the clay sediments would have been transported over a very long distance, majorly by gravity flows, to these regions. But the associated terrestrial silts in our studied mudstones are nearly pure quarts and are moderately to well sorted. Features associated with gravity deposits are not present in them. Besides that, in the Lower Zhangxia Formation, there are sets of multilithological intervals which are composed of muddy limestones and mudstones (Fig. 3), and interpretation that mudstones are products on abyssal basin might not be totally reasonable because this will be dependent on whether the sea level is able to change so frequently to form these thin beds in a short time or not. In fact, it is difficult to accept models suggesting rapid and frequent change of sea level from fairly deep to shallow marine for the formation of rocks. Thus, we suggest that mudstones of the Lower Zhangxia Formation formed in the clastic shallow marine which is an area adjacent to both restricted platform and clastic tidal flat.

Furtherly, based on our interpretation of these facies, it is easier to reconstruct the history of sea level change in the Lower Zhangxia Formation. From our findings, we can propose that the oolitic limestones of this studied formation 


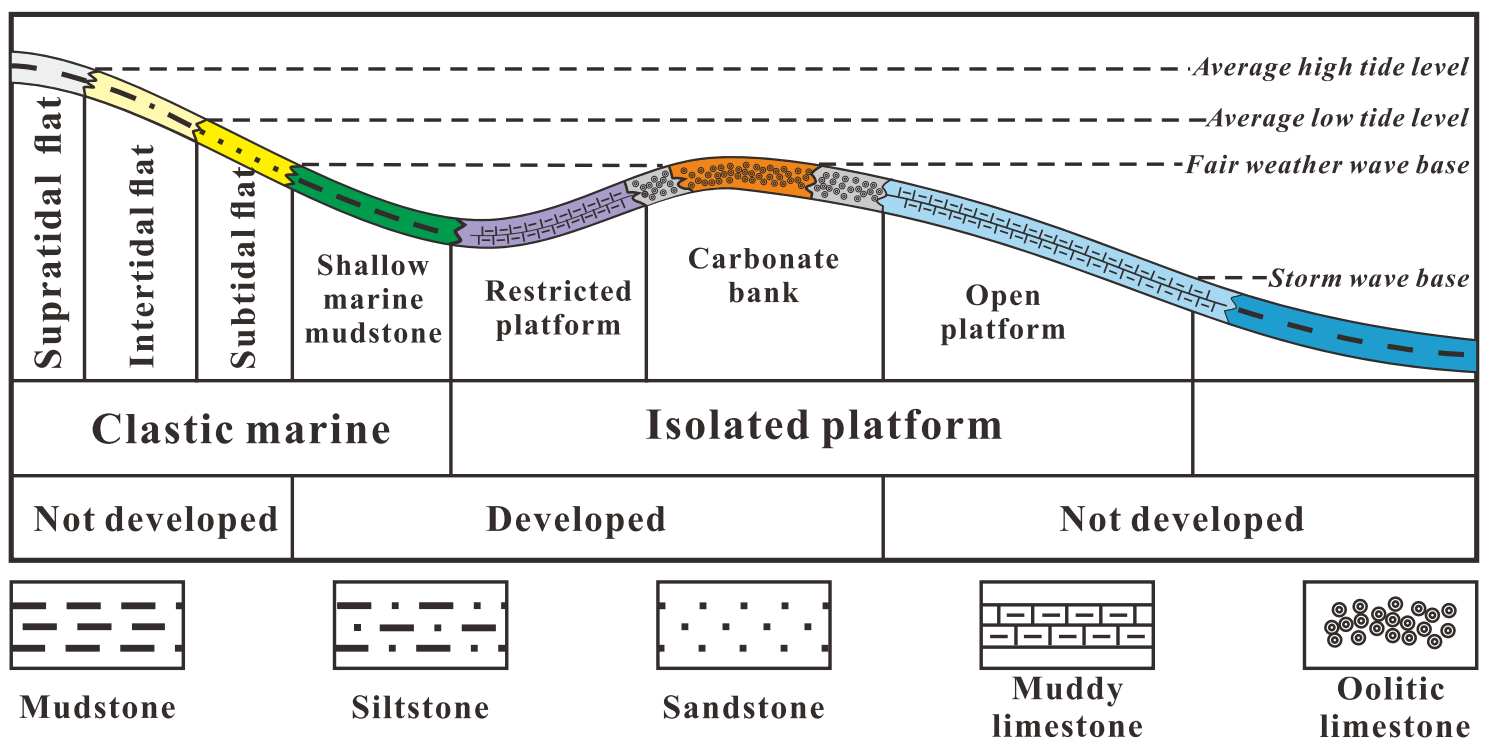

Fig. 16. Depositional model of the Lower Zhangxia Formation at Xiaweidian (modified from Wang et al., 1990; Feng et al., 1994, 2004; Jin et al., 2013; Guo et al., 2019).This model consists of clastic marine and isolated platform. Shallow marine, restricted platform and carbonate bank are adjacent and the reasonable depositional areas for the studied rocks.

dominantly formed as a result of sea level fall.

\section{Conclusions}

Detailed understanding of rock features such as lithology, texture, sedimentary structures and fossil content as well as other distinct features of rock facies is always required to interpret depositional environments of sedimentary rocks. But multiple solutions of interpretation of these environments can still exist, due to different study interests and dissimilar evidence in hand. Approaches employed by researchers thus go a long way toward understanding whether appropriate interpretations will be made or not. Using a multi-proxy approach has been proven to be more useful than uni-proxy approach. And this approach does provide enough data which can be correlated before a final decision is made on the interpretation.

The Middle Cambrian Lower Zhangxia Formation at Xiaweidian contains four types of rocks: oolitic limestone, muddy limestone, calcareous mudstone and flat-pebble limestone. Previous authors majorly suggested two depositional models for this formation (Wang et al., 1990; Zhang et al., 2009; Mei, 2011; Jing et al., 2015; Kang et al., 2016; Ma et al., 2017; Ni, 2017; Guo et al., 2019).

Our current study which involve detailed bed by bed logging of rock exposures of the Lower Zhangxia Formation at Xiaweidian has helped shed more light on the nature of deposition of these sediments. Lithologic characteristics and other properties of rocks have been studied through thin sections, SEM and EDS. Evidence from content of limemud and features of ooids within the oolitic limestone has led to our suggestion that these rocks were formed in an intermittent high-energy bank. In addition, features of bioherm within the muddy limestone corroborate this suggestion. Re- stricted platform that exists between clastic shallow marine and carbonate bank, served as the depositional site for the muddy limestone, due to the low wave energy experienced by the restricted platform, occurrences of pyrites inside muddy limestones which shows evidence for their formation in this reducing environment, and input of terrestrial clays indicating their deposition adjacent to clastic environment. Flat-pebble limestones, having similar composition to muddy limestones, were also the sedimentation products on restricted platform below the fair-weather wave base. Input of terrestrial silts in the analyzed mudstones suggests the relation to clastic environment near the land, i.e. clastic shallow marine, and they were not gravity deposits of outer ramp and abyssal basin, as supported by features in composition, textures of silts and structures of mudstones. The existence of thick oolitic limestones in this formation can be rationally explained as result of sea level falling during their deposition. This study demonstrates the application of a mixed carbonate-clastic model in the Lower Zhangxia Formation at Xiaweidian and this model can also be applicable to other formations of the North China.

\section{Acknowledgement}

This study was financially supported by the National Natural Science Foundation of China (No. 41872148). The authors are grateful to Zengzhao Feng (China University of PetroleumBeijing, CHN), Donggao Zhao (University of Missouri-Kansas City, USA), Jun Li (Xi' an Shiyou University, CHN) and other anonymous reviewers who have contributed immensely to improve this manuscript. 


\section{Conflict of interest}

The authors declare no competing interest.

Open Access This article, published at Ausasia Science and Technology Press on behalf of the Division of Porous Flow, Hubei Province Society of Rock Mechanics and Engineering, is distributed under the terms and conditions of the Creative Commons Attribution (CC BY-NC-ND) license, which permits unrestricted use, distribution, and reproduction in any medium, provided the original work is properly cited.

\section{References}

Adams, A., Mackenzie, I. Carbonate Sediments and Rocks Under the Microscope: A Colour Atlas. Barcelona, Spain, CRC Press, 1998.

Adams, A.E., MacKenzie, W.S., Guilford, C. Atlas of Sedimentary Rocks Under the Microscope. London, UK, Routledge, 2017.

Barker, A.J. A Key for Identification of Rock-Forming Minerals in Thin Section. London, UK, CRC Press, 2014.

Bathurst, R.G.C. Carbonate Sediments and Their Diagenesis. Amsterdam, The Netherland, Elsevier, 1972.

Burchette, T.P., Wright, V.P. Carbonate ramp depositional systems. Sediment. Geol. 1992, 79(1-4): 3-57.

Chambers, R.M., Fourqurean, J.W., Macko, S.A., et al. Biogeochemical effects of iron availability on primary producers in a shallow marine carbonate environment. Limnol. Oceanogr. 2001, 46(6): 1278-1286.

Crawford, C.B., Quinn, B. Microplastic identification techniques, in Microplastic Pollutants, edited by C.B. Crawford, Elsevier, Amsterdam, pp. 219-267, 2017.

Davies, P.J., Bubela, B., Ferguson, J. The formation of ooids. Sedimentology 1978, 25(5): 703-730.

Dunham, R.J. Classification of carbonate rocks according to depositional textures, in Classification of Carbonate Rocks, edited by W.E. Ham, American Association of Petroleum Geologists Memoir 1, Tulsa, pp. 108-121, 1962.

Feng, Z. Lithofacies paleogeography of the Cambrian and Ordovician in China. Beijing, Petroleum Industry Press, 2004. (in Chinese)

Guo, Q., Jin, Z., An, Y., et al. Study on sedimentary environments and patterns of Cambrian Zhangxia Formation at Xiaweidian, Beijing. Acta Sedimentologica Sinica 2019, 37(1): 40-50. (in Chinese)

Haldar, S.K. Introduction to Mineralogy and Petrology. Amsterdam, The Netherlands, Elsevier, 2013.

He, Y., Liu, B., Qin, S., et al. The bioherm and geological significance of Middle Cambrian Zhangxia Formation at Xiaweidian profile in West Hill, Beijing, China. Geological Science and Technology Information 2012, 31(1): 9-15. (in Chinese)

Hu, T., Pang, X., Jiang, S. Impact of paleosalinity, dilution, redox, and paleoproductivity on organic matter enrichment in a saline lacustrine rift basin: A case study of Paleogene organic-rich shale in Dongpu Depression, Bohai Bay Basin, Eastern China. Energy Fuels 2018, 32(4): 50455061.

James, N.P., Debrenne, F. Lower Cambrian bioherms: Pioneer reefs of the Phanerozoic. Acta Palaeontol. Pol. 1980, 25(3-4): 655-668.

Jin, Z., Shi, L., Gao, B., et al. Carbonate facies and facies models. Acta Sedimentologica Sinica 2013, 31(6): 965979. (in Chinese)

Jing, Y., Liu, J., Yan, Z., et al. Reconstructing sea-level changes from types of storm deposits: An example of the middle and late Cambrian at Xiaweidian Section of Western Hills, Beijing. Journal of Palaeogeography 2015, 17(5): 653-668. (in Chinese)

Kang, S., Shao, L., Yi, Q., et al. Study on cambrian petrology and sedimentary environments at Xiaweidian Area, Western Beijing. Coal Geology of China 2016, 28(6): 1-8. (in Chinese)

Kiessling, W., Flügel, E., Golonka, J. Patterns of phanerozoic carbonate platform sedimentation. Lethaia 2003, 36(3): 195-225.

Ma, Y., Mei, M., Zhou, R., et al. Forming patterns for the oolitic bank within the sequence-stratigraphic framework: An example from the Cambrian series 3 at the Xiaweidian section in the Western Suburb of Beijing. Acta Petrologica Sinica 2017, 33(4): 1021-1036. (in Chinese)

Mei, M. Depositional trends and sequence-stratigraphic successions under the Cambrian second-order transgressive setting in the North China Platform: A case study of the Xiaweidian section in the western suburb of Beijing. Geology in China 2011, 38(2): 317-337. (in Chinese)

Mei, M., Ma, Y., Mei, S., et al. Framework of Cambrian sedimentary sequence and evolution of carbonate platform in North China. Geoscience 1997, 3: 16-23. (in Chinese)

Meng, X., Ge, M., Tucker, M.E. Sequence stratigraphy, sealevel changes and depositional systems in the CambroOrdovician of the North China carbonate platform. Sediment. Geol. 1997, 114(1-4): 189-222.

Myrow, P.M., Tice, L., Archuleta, B., et al. Flat-pebble conglomerate: Its multiple origins and relationship to metre-scale depositional cycles. Sedimentology 2004, 51(5): 973-996.

$\mathrm{Ni}, \mathrm{S}$. Forced regressive sediments in the Zhangxia Formation at the Xiaweidian section in the western suburb of Beijing. Journal of Stratigraphy 2017, 41(1): 103-109. (in Chinese)

Nichols, G. Sedimentology and Stratigraphy. West Sussex, UK, John Wiley \& Sons, 2009.

Purkis, S., Kerr, J., Dempsey, A., et al. Large-scale carbonate platform development of Cay Sal Bank, Bahamas, and implications for associated reef geomorphology. Geomorphology 2014, 222: 25-38.

Rankey, E.C., Schlaich, M., Mokhtar, S., et al. Seismic architecture of a Miocene isolated carbonate platform and associated off-platform strata (Central Luconia Province, offshore Malaysia). Mar. Pet. Geol. 2019, 102: 477-495.

Read, J.F. Carbonate platform facies models. AAPG Bull. 1985, 69(1): 1-21.

Roane, T.M., Pepper, I.L. Microscopic techniques, in Environmental Microbiology, edited by L.P. Ian, P.G. Charles 
and J.G. Terry, Elsevier, Amsterdam, pp. 177-193, 2015. Scholle, P.A., Ulmer, D.S. A Color Guide to the Petrography of Carbonate Rocks: Grains, Textures, Porosity, Diagenesis. Tulsa, USA, American Association of Petroleum Geologists Memoir 77, 2003.

Sepkoski, J.J. Flat-pebble conglomerates, storm deposits, and the Cambrian bottom fauna, in Cyclic and Event Stratification, edited by G. Einsele and A. Seilacher, Springer, Berlin, pp. 371-385, 1982.

Summons, R.E., Bird, L.R., Gillespie, A.L., et al. Lipid biomarkers in ooids from different locations and ages: Evidence for a common bacterial flora. Geobiology 2013, 11(5): 420-436.

Sumner, D.Y., Grotzinger, J.P. Numerical modeling of ooid size and the problem of Neoproterozoic giant ooids. J. Sediment. Res. 1993, 63(5): 974-982.

Tanaka, N., Takakura, A., Miyatake, N., et al. Comparison of histological findings and the results of energy-dispersive $\mathrm{X}$-ray spectrometry analysis in experimental electrical injury. Legal. Med. 2018, 31: 20-23.

Trower, E.J., Lamb, M.P., Fischer, W.W. Experimental evidence that ooid size reflects a dynamic equilibrium between rapid precipitation and abrasion rates. Earth Planet Sci. Lett. 2017, 468: 112-118.

Tucker, M.E. Shallow-marine carbonate facies and facies models. Geological Society, London, Special Publications 1985, 18(1): 147-169.
Wang, C., Fan, K., Yin, Z. Features of ooids in the Middle Cambrian Zhangxia Formation in the Western Hills, Beijing, and their environmental significance. Bulletin of Chinese Academy of Geological Sciences 1990, 22: 39-55. (in Chinese)

Yu, K., Chang, T., Qiu, L., et al. Research development of Flat-pebble conglomerate characteristics and their origin in early paleozoic North China platform. Acta Sedimentologica Sinica 2015, 33(6): 1111-1125. (in Chinese)

Zampetti, V., Schlager, W., van Konijnenburg, J.H., et al. Architecture and growth history of a Miocene carbonate platform from 3D seismic reflection data; Luconia province, offshore Sarawak, Malaysia. Mar. Pet. Geol. 2004, 21(5): 517-534.

Zhang, X., Zhang, N., Yang, Z., et al. Carbonate microfacies and sedimentary facies of Middle Cambrian Formation at Xiaweidian profile in Western Hills, Beijing, China. Geological Science and Technology Information 2009, 28(6): 25-30. (in Chinese)

Zhang, Y., Wan, Y. Origin of the flat pebble conglomerates in the Western Hills, Beijing. Bulletin of Chinese Academy of Geological Sciences 1990, 22: 57-64. (in Chinese)

Zhu, C., Luo, Y., Yang, S., et al. Sequence stratigraphy of Cambrian in Western Hills, Beijing. Geology in China 2009, 36(1): 120-130. (in Chinese) 